\title{
RESEARCH
}

\section{EFFECT OF MUSIC THERAPY ON ANXIETY AND SLEEP QUALITY OF GERIATRIC HAEMATOLOGICAL ONCOLOGY PATIENTS}

Turkish Journal of Geriatrics

DOI: 10.31086/tjgeri.2020.193

2020; 23(4): 546-554

- Kübra GÖKALP ${ }^{1}$ (D)

- Mine EKINCi ${ }^{1}$ iD

CORRESPONDANCE

Kübra GOKALP

Atatürk University, Faculty of Nursing,

Erzurum, Turkey

Phone: +904422314556

e-mail: kubragungormus2010@hotmail.com

Received: Jun 01, 2020

Accepted: Nov 10, 2020

\section{Abstract}

Introduction: Psychiatric symptoms that develop with the diagnosis of cancer are important in terms of affecting the severity of the patient's physical illness. This study was carried out to determine the effect of music therapy on anxiety and sleep quality of geriatric haematological oncology patients.

Materials and Methods: This experimental clinical trial, a pretest-posttest study, was conducted with 60 older hematologic cancer patients. The patients were sorted into control and experimental groups $(n=30$ in the control group; $n$ $=30$ in the experimental group). Data was collected via a sociodemographic form, the Pittsburgh Sleep Quality Index, and the State-Trait Anxiety Inventory. The participants in the experimental group listened to music every day for one week while the control group was not exposed to any intervention.

Results: There was no statistically significant difference between the pretest Pittsburgh Sleep Quality Index and State-Trait Anxiety Inventory mean scores of the experimental and control groups. Pittsburgh Sleep Quality Index and StateTrait Anxiety Inventory mean score of the experimental group were lower than the control groups.

Conclusion: The intervention of music therapy was found to have an effect in reducing anxiety and increasing sleep quality of patients. Music therapy can be used as an alternative method of treating the anxiety and increasing the sleep quality of geriatric hematology patients.

Keywords: Nursing; Hematology; Patients; Aged 


\section{INTRODUCTION}

Cancer, followed by cardiovascular disease as the death cause, is one of the most serious health problems in the world, having adverse physical, psychological, social, and economic effects on individuals, families, and societies (1). According to the World Health Organization (WHO) and the International Agency for Research on Cancer, 18 million people were diagnosed with cancer worldwide in 2018, and 9 million of these cases constituted individuals 65 years and over (1). Hematological cancers constitute more than half of cancers in this age group (2). Although diseases such as leukemia, myeloma, and lymphoma are more likely to be seen in older adults than the young people, studies have concentrated on children because leukemia ranks first among childhood cancers (1).

Age is one of the important determinants of cancer, and the incidence of cancer is increasing as the older population increases (1). The percentage of older adults in Turkey has risen to $9.1 \%$. It is predicted that if the rate of total fertility and death continues in the same way, the percentage of those 65 years old and over will increase to $10.2 \%$ in 2023 and $20.8 \%$ in 2050 (3). Considering that older patients have more difficulty adapting to environmental changes and innovations compared to younger patients, it could be predicted that the psychological problems of older cancer patients will increase in importance day-by-day $(2,4)$.

Psychiatric symptoms that develop with the diagnosis of cancer are important in terms of affecting the severity of the patient's physical illness, disease course, treatment response and the patient's quality of life and care (5). Research shows that nearly half of cancer patients have psychiatric disorders that need to be treated, such as anxiety, depression, organic psychiatric disorders, and personality disorders (2, 4). At the same time, sleep disorders are a common but often neglected problem in cancer patients (6). Medical treatments applied to a patient who is struggling with cancer (such as chemotherapy, ra- diotherapy, or surgical operations) could also be the cause of psychiatric symptoms, such as steroid treatment causing depression (7). Cancer requires holistic care and should receive multidisciplinary treatment (5-7). A consultation liaison psychiatry nurse should work in collaboration with other members of the treatment team, with holistic care given to the patient and their families (8). There are some complementary treatments for psychological symptoms like relaxation therapy, hypnosis, meditation/mindfulness-based stress reduction, yoga and acupuncture which among these the music therapy is also included (9). Music therapy, which is a psychosocial approach, complements the treatment of health problems, such as cancer, and is used as an alternative treatment $(9,10)$.

Music has been used in hospitals for a variety of reasons from the past to the present. It is known that music affects the areas in the human brain related to emotions such as happiness, joy, anger, and hate and has an important effect on human beings $(9,10)$. Music influences the limbic system of the brain, modulating endogenous opioids and oxytocin, producing relaxation and well-being; music also accelerates or slows breathing and changes a person's internal state; affects heart rhythm and blood pressure, reduces muscle tension and improves movement and coordination (9). These features of music are considered as therapeutic factors (8-10).

There are limited studies on older patients with hematologic cancers in the Turkish literature $(4,2)$. Considering the focus on children in previous studies on hematological cancers, this study is important in terms of determining the effectiveness of music therapy on anxiety and sleep quality experienced by older hematologic cancer patients and shedding light on nursing care (11). This study was the first one that explored the effectiveness of the music therapy on geriatric haematological oncology patients in Turkey.

The study hypotheses are as follows:

H1: Music therapy given to geriatric haemato- 
Table 1. Demographic status of individuals in experimental and control groups

\begin{tabular}{|c|c|c|c|c|c|}
\hline \multirow[b]{2}{*}{ Characteristics } & \multicolumn{2}{|c|}{ Control Group } & \multicolumn{2}{|c|}{ Experimental Group } & \multirow[b]{2}{*}{$p$} \\
\hline & $\mathbf{n}$ & $\%$ & $\mathbf{n}$ & $\%$ & \\
\hline \multicolumn{6}{|l|}{ Gender } \\
\hline Female & 14 & 46.7 & 13 & 43.3 & $\chi^{2}=0.67$ \\
\hline Male & 16 & 53.3 & 17 & 56.7 & $p=0.795$ \\
\hline \multicolumn{6}{|l|}{ Marriage status } \\
\hline Maried & 24 & 80 & 22 & 73.4 & $\chi^{2}=0.373$ \\
\hline Single & 6 & 20 & 8 & 26.6 & $p=0.542$ \\
\hline \multicolumn{6}{|l|}{ Education level } \\
\hline Primery school & 19 & 63.3 & 20 & 66.6 & $\chi^{2}=0.373$ \\
\hline High school & 9 & 30 & 9 & 30 & $p=0.946$ \\
\hline Universty & 2 & 6.7 & 1 & 3.4 & \\
\hline \multicolumn{6}{|l|}{ Diagnosis of disease } \\
\hline 1 year and $\downarrow$ & 11 & 36.7 & 13 & 43.3 & $\chi^{2}=0.281$ \\
\hline 2-4 year & 11 & 36.7 & 10 & 30 & $p=0.869$ \\
\hline 5 year and $\uparrow$ & 8 & 26.6 & 7 & 26.7 & \\
\hline \multicolumn{6}{|l|}{ Stage of cancer } \\
\hline Stage II & 14 & 46.7 & 17 & 56.7 & $\chi^{2}=0.601$ \\
\hline Stage III & 16 & 53.3 & 13 & 43.3 & $p=0.438$ \\
\hline \multicolumn{6}{|l|}{ Duration of stay in hospital } \\
\hline 14 day and $\downarrow$ & 6 & 20 & 4 & 13.4 & $\chi^{2}=0.518$ \\
\hline $15-20$ day & 16 & 53.4 & 18 & 60 & $p=0.772$ \\
\hline \multirow[t]{2}{*}{20 day and $\uparrow$} & 8 & 26.6 & 8 & 26.6 & \\
\hline & \multicolumn{4}{|c|}{$\mathrm{M} \pm \mathrm{SD}$} & \\
\hline \multirow[t]{2}{*}{ Age (year) } & $72.13 \pm 4.03$ & & $73.14 \pm 4.18$ & & $M W-U=153.500$ \\
\hline & & & & & $p=0.630$ \\
\hline
\end{tabular}

$\chi^{2}=$ chi-square test. MW-U = MannWhitney $U$ test.

logical oncology patients does not affect their levels of anxiety and sleep quality.

H2: Music therapy given to geriatric haematological oncology patients does affect their levels of anxiety and sleep quality.

\section{MATERIALS AND METHODS}

The study was conducted through an experimental method with pretest-posttest control group design from May-November 2015 with older hematologic cancer patients in Turkey. The study was conducted in a university hospital's hematology clinic in the 
Table 2. A comparison of total pre-test and post-test PSQI score mean for individuals in the experimental group and the control group

\begin{tabular}{|c|c|c|c|c|}
\hline \multirow{2}{*}{ Groups } & \multirow{2}{*}{$\begin{array}{l}\text { Pre-test } \\
\mathrm{M} \pm \mathrm{SD}\end{array}$} & \multirow{2}{*}{$\begin{array}{l}\text { Post-test } \\
M \pm S D\end{array}$} & \multicolumn{2}{|c|}{ Within groups } \\
\hline & & & $\mathbf{t}$ & $p$ \\
\hline Control group & $14.50 \pm 2.70$ & $13.87 \pm 2.90$ & $t=0.615$ & $p=0.543$ \\
\hline Experimental group & $14.56 \pm 2.00$ & $10.67 \pm 2.73$ & $t=4.566$ & $p=0.000^{\star}$ \\
\hline \multicolumn{5}{|l|}{ Between group } \\
\hline $\mathrm{t}$ & $t=-1.439$ & $t=3.819$ & & \\
\hline $\mathrm{p}$ & $p=0.161$ & $p=0.001 *$ & & \\
\hline
\end{tabular}

$* p<0.05$

east of Turkey.

The population of the study consisted of older (65 years and over) hematologic cancer patients. On the basis of the power analysis, we determined the required sample size as total 54 , including 27 patients each in the experimental and control groups, with 95\% confidence interval, 90\% power, and 5\% error margin with a significance level of $p=.05$ (12). A total of 60 hematological cancer patients, 30 of whom were the control group and 30 of which were the experimental group, were included. The data collection tool was provided to the individuals who volunteered to participate in the study.

Inclusion criteria of the study:

- Having at least eleven days of inpatient treatment in hematology services.

- Receiving chemotherapy treatment.

- Being a host for disease II or III.

- Being able to cooperate and communicate

- Not using psychiatric or sleep medicine.

- Absence of radiation therapy.

\section{Measurements}

The Sociodemographic Form, the Pittsburgh
Sleep Quality Index (PSOI), and the State-Trait Anxiety Inventory (STAI) were used for data collection. The participants in the experimental group listened to music every day for one week, while the control group did not listen to music during the study.

\section{Sociodemographic Form}

The Sociodemographic Form, created by the researchers, was consisted of seven questions (age, gender, marrital status, education level, the time since the diagnosis of disease, stage of cancer and the duration of stay in hospital) including ones to obtain the sociodemographic characteristics of the patients.

\section{Pittsburgh Sleep Quality Index}

The PSQI was used to assess the subjective sleep quality in all patients. The 18 items included in the scoring are grouped into 7 component points. Some of the components are specified with a single item, while others are obtained by grouping several substances. Each item is evaluated between 0-3 points. The total score has a value between 0-21. A higher score indicates a lower level of sleep quality (13). The reliability and validity of this scale for Turkey was determined in 1996 (14). Cronbach's alpha 
reliability coefficient of the scale was found to be 0.80 (14). In this study, Cronbach's alpha reliability coefficient was 0.79 .

\section{State-Trait Anxiety Inventory}

We measured anxiety using the STAl, developed by Spielberger, Gorsuch, and Lushene (1970) (15). The validity and reliability of this inventory for Turkey were determined in 1983 (16). The inventory has two separate scales with 20 items, each a four-point Likert type. The inventory consists of two parts: STAI1 , which measures the state anxiety (SA) level, and STAI-2, which measures the trait anxiety (TA) level. The total score obtained from both scales ranges from 20 to 80. A higher score indicates a higher level of anxiety. In this study, Cronbach's alpha reliability coefficient for the SA inventory was 0.84 ; the TA inventory's coefficient was 0.95 .

\section{Study Procedure}

Data from the control group were collected first, to prevent any interference between patients, then data from the experimental group were collected. The interviewer primarily gave information to both groups and then the data were collected using the face-to-face interview technique in the clinic. The data were collected by interviewing each patient for a mean of 10 to 15 minutes in the hematological clinic.

The data were collected 48 hours after treatment because patients experienced intensive side effects related to the first 48 hours after chemotherapy treatment. On post chemotherapy days 3 to 10, we asked the participants to fill the Sociodemographic Form, PSQI, and STAI and recorded their responses.

The data from the control group were collected within the specified time frame using the data collection tools as mentioned above after implementation of routine in the clinic.

Data from the experimental group were collected after applying music therapy, and the data were collected using the same data collection tools as used for the control group. Music therapy was performed for the experimental group's members every day for one week

\section{Application of Music Therapy}

During the selection of the type of music compositions, the choice of music was designated by Oruc Güvenc who was a lecturer in the Department of Occupational Therapy at the Faculty of Health Sciences. He made a clinical psychology doctorate in music therapy at the Department of Psychiatry, the Cerrahpasa Faculty of Medicine. He founded Turkish Music Research and Promotion Group (TUMETA). He recommended Hejaz, Husseini and Neva compositions (nonverbal instrumental music) from the music and health series prepared by TUMATA (17). Hejaz composition has a therapeutic effect on bones, brain and children's diseases. It has a strong effect on the uro-genital system and kidneys. It gives a sense of humility. Husseini composition is useful for the heart, liver and stomach. It gives a sense of peace. Neva composition is useful in treating mental illnesses. It generates feelings of strength and heroism (17).

Patients laid back and listened to the music with earphones in their rooms. It was explained to the patients how to use their earphones and how to turn them on and off. The researchers observed the patients listening to music, without disturbing them. Each music therapy application took about 30-40 minutes every night for seven days. In the control group, three patients were unable to perform a post-test because one left the hospital early and the other two patients died in the hospital during treatment. In the experimental group, posttest data could not be collected from four patients because two of them were isolated because of the risk of infection, one patient died in the hospital during treatment, and one patient left the hospital early. New patients who met the inclusion criteria were included in the research as substitutes. 


\section{Statistical Analysis}

The SPSS package program was used to evaluate the data. For the assessment of patients' descriptive characteristics percentage, arithmetic mean, and standard deviation were used. The chi-square test was also used to look at group homogeneity, and independent and dependent sample t-tests were used to analyze relationships among pretestposttest scores in hematology patients. The level of significance was set at $p<.05$.

\section{Ethical Considerations}

After obtaining permission from the ethics committee of the Faculty of Health Sciences (approval number 2014-6/8), written permission was obtained from the hospital. The necessary information was given to the patients who took part in the study; their questions were answered and written permission was obtained from them. Since the use of humans in the study required protection of individual rights, informed consent, voluntary basis, and protection of confidentiality, which are relevant ethical principles, were realized.

\section{RESULTS}

Table 1 presents the characteristics of the control and experimental group. Regarding the sociodemographic status of the control and experimental group, the two groups were similar in terms of age, gender, marrital status, education level, the time since the diagnosis of disease, stage of cancer and the duration of stay in hospital $(p>.05)$.

As seen in Table 2, there was no significant difference between pre-test and post-test PSQI mean scores of the control group patients $(t=.615, p=$ .543). In contrast, the difference between the pretest and post-test PSOI mean scores of the experimental group's patients was statistically significant $(\mathrm{t}=4.566, \mathrm{p}=.000)$.

The pre-test PSQI mean score of patients in the control group was $14.50 \pm 2.70$, while the pre-test
PSQI mean score of patients in the experimental group was $14.56 \pm 2.00$. No statistically significant difference was found between pre-test mean of the groups ( $t=-1.439, p=.161$ ). The post-test PSQl mean score of patients in the control group was $13.87 \pm 2.90$, while the post-test PSQI mean score of patients in the experimental group was $10.67 \pm 2.73$. Statistically significant difference was found between post-test mean of the groups $(t=3.819, p$ $=.001$ ).

According to Table 3, there was no statistically significant difference between the pre-test and post-test SA ( $t=1.782, p=.085)$ and TA $(t=.143$, $\mathrm{p}=.887)$ mean scores of the control group. There was a statistically significant difference between the pre-test and posttest SA mean scores $(t=4.715, p$ $=.000)$ and TA mean scores $(t=2.630, p=.014)$ of the hematology patients in the experimental group.

The post-test SA mean score of patients in the control group was $40.23 \pm 11.30$, while the posttest SA mean score of patients in the experimental group was $35.43 \pm 10.12$. The difference between the groups' post-test SA mean scores was statistically significant $(t=3.799 p=.008)$. The post-test TA mean scores of hematology patients in the control group was $35.90 \pm 9.82$, while the post-test TA mean scores of the experimental group was 33.60 9.43 . The difference between the groups' post-test TA mean scores was statistically significant $(t=2.483$, $\mathrm{p}=.019)$

\section{DISCUSSION}

This study found that music therapy had effects in reducing anxiety and increasing sleep quality. Music therapy, which is a psychosocial initiative, is used as a complementary and alternative treatment of health-related problems, such as cancer (10). It is a fact that music influences the emotional areas related to perceptions such as happiness, joy, sorrow, anger, and hatred in the human brain and has an important effect on humans in this regard. This feature of music is considered a therapeutic factor $(9,10)$. 
In this study, it was found that the decrease between the pre-test and post-test PSOI scores of the experimental group was statistically significant; there was no statistically significant difference between the pre-test and post-test scores of the control group. This was consistent with the results of the related studies on sleep quality. Wang, Sun, and Zang (6) observed that music improved sleep quality in elderly people. Lafci, and Oztunc (18) found that relaxing classical music was an effective intervention in reducing sleeping problems. Blanaru, et al. (19) found that music therapy increased sleep efficiency in post-traumatic stress disorder patients. Kumar (20) studied music therapy's effect on the level of melatonin (a hormone affecting sleep and mood) in Alzheimer's patients; it was found that melatonin secretion increased after music therapy, and it was emphasized that music therapy was effective on the psychological and physiological characteristics of the patients. Thus, it can be concluded that music therapy can improve sleep quality in geriatric hematological oncology patients.

When the STAI score variations of both groups were examined, the decrease in the scores of the experimental group was significantly higher than the decrease in the scores of the control group. These findings parallel those of the existing literature. Zhou, et al. (21) found music therapy reduced depression and anxiety in female cancer patients. Palmer, et al. (22) similarly observed a significant decrease in anxiety levels of a group of women receiving music therapy who had surgery for the diagnosis or treatment of breast cancer. Rossetti, et al. (23) determined that music therapy for cancer patients resulted in decreased patient anxiety and distress. Bilgic, and Acaroglu (24) studied effect of listening to music on the comfort of chemotherapy patients; it was found that anxiety decreased after music. Umbrello, et al. (25) found that music therapy is associated with a reduction in anxiety of critically ill patients. This finding suggests that the music therapy intervention showed clinical efficacy for anxiety.

Therefore, music therapy that was given to various groups has been found to be effective in reducing anxiety and increasing sleep quality. The results of our study are in accordance with the results of the studies in the literature of geriatric haematological oncology patients. These results confirm the hypothesis $\mathrm{H} 2$, that "Music therapy given to geriatric haematological oncology patients does affect their levels of anxiety and sleep quality."

\section{CONCLUSION}

In this study, it was found that music therapy decreased PSQI and STAI mean scores of the experimental group. As a result of these findings it can be said that music therapy increases sleep quality and decreases the anxiety of geriatric oncology patients.

The findings of this study may provide a basis for future research with regard to evaluating the use of music therapy in the management of sleep quality and anxiety in various geriatric hematology patients. In line with this conclusion, it is suggested that music therapy be used in nursing practice. Nurses should use music therapy, which is a non-pharmacological method, in their practice because it is a safe and cheap method which may be used to treat sleep disorders and anxiety.

\section{CONFLICT OF INTEREST STATEMENT}

None

\section{ACKNOWLEDGMENT}

We would like to thank the geriatric oncology patients who participated in this study and deceaset Oruc Güvenc. 


\section{REFERENCES}

1. International Agency for Research on Cancer 2018. [Internet] Available from: https://gco.iarc.fr/today/ home. Accessed: 03.08.2020

2. Ovayolu O, Ovayolu N. Acupressure and fatigue in geriatric hematologic malignancies. J Health Sci Erciyes Uni 2017; 4(1): 6978. (in Turkish). [Internet] Available from: https://pdfs.semanticscholar.org/4c5d/ b378739ecb327168d8007c3a645fc5522cd2.pdf. Accessed:02.08.2020

3. Resaults of Population Censuses 1935-2000 and Results of Address Based Population Registiration System, 2007-2019. [Internet] Available from: http:// www.tuik.gov.tr/UstMenu.do?metod=temelist. Accessed:05.08.2020.

4. Bostankolu O, Ozturk B, Coskun U, Buyukberber S, Benekli, M. Cancer chemotherapy in elderly patients. Int J Hematol and Oncol 2008; 18(3): 18692. (in Turkish). [Internet] Available from: http:// thod.org/pdf/PDF_333.pdf. Accessed:16.05.2020.

5. Nightingale $\mathrm{CL}$, Rodriguez $\mathrm{C}$, Carnaby $\mathrm{G}$. The impact of music interventions on anxiety for adult cancer patients, a meta-analysis and systematic review. Integr Cancer Ther 2013; 12(5): 393-403. (PMID: 23625027).

6. Wang $C F$, Sun $Y L$, Zang HX. Music therapy improves sleep quality in acute and chronic sleep disorders: A meta-analysis of 10 randomized studies. Int J Nursing Studies 2014; 51(1): 51-62. (PMID: 23582682).

7. Liu MC, Ko KT, Lee CS. Atypical depression associated with high-dose steroid treatment in an adolescent patient receiving liver transplantation. TaiwaN J Psychiatry 2019; 33 (2): 114-5. (DOI: 10.4103/TPSY.TPSY_21_19).

8. Yildirim S, Simsek E, Geridönmez K, Basma S, Vurak $U$. Examination of the knowledge and practices of nurses about consultation liaison psychiatry nursing. Journal Psychiatric Nurs 2019; 10(2):96-102. (DOI: 10.14744/phd.2019.21548).

9. Satija A, Bhatnagar S. Complementary therapies for symptom management in cancer patients. Indian J Palliat Care 2017; 23(4), 468-79.( PMID: 29123357).

10. Coban A. (Eds). Music Therapy, Music Therapy for Mental Health.1st edition, İstanbul, Timas Press, Turkey 2020, pp 126-350.

11. Bagcivan G, Uysal N, Karaaslan A, Kapucu S, Talas MS, Terakye G. Turkey between the years 20092013 which was published examination of oncology research in the field of nursing: systematic review. Turk J Oncol 2015; 30(Suppl 1): 5-15. (in Turkish). (DOI: 10.5505/tjoncol.2015.1195).

12. Capık C. Use of confirmatory factor analysis in validity and reliability studies. J Anatolia Nurs and Helath Sci 2014; 17(3): 196-205. (in Turkish) [Internet] Available from: https://dergipark.org.tr/en/download/articlefile/29691. Accessed:28.07.2020.

13. Buysse DJ, Reynolds CF, 3rd Monk TH, Berman SR, Kupfer DJ. The Pittsburgh Sleep Quality Index: a new instrument for psychiatric practice and research. Psychiat Reserch 1989; 28: 193-213. (PMID: 2748771).

14. Agargun MY, Kara $H$, Anlar $O$. The validity and reliability of Pittsburgh Sleep Quality Index. Turkish Psychiatry Rev 1996; 7(Suppl 2): 107-15. (in Turkish) [Internet] Available from: http://www.turkpsikiyatri. $\mathrm{com} / \mathrm{en} /$ default.aspx? modul=summary\&id=210. Accessed:16.04.2020.

15. Spielberger CD, Gorsuch RL, Lushene RE. (Eds.). Manual for the State-Trait Anxiety Inventory. Palo Alto, Consulting Psychologists Press, USA 1970, pp 3-28.

16. Oner N, LeCompte A. State-Trait Anxiety İnventory Hand Book.1st edition, İstanbul, Bogazici University, Turkey 1983, pp 1-26.

17. Turkish Music Research and Promotion Group. [Internet] Available from: https://tumata.com/ muzik-terapi/turk-muzigi-makamlari-ve-etkileri/. Accessed: 03.08.2020

18. Lafci $D$, Oztunc $G$. The effect of music on the sleep quality of breast cancer patients. Int J Caring Sciences 2015; 8(3): 633-40. [Internet] Available from: https://www.internationaljournalofcaringsciences. org/docs/14_Laftci_original_8_3.pdf. Accessed:16.04.2020.

19. Blanaru $M$, Bloch $B$, Vadaz $L$ et al. The effects of music relaxation and muscle relaxation techniques on sleep quality and emotional measures among individuals with posttraumatic stress disorder. Ment Illn 2012; 4(13): 59-65. (PMID: 25478114).

20. Kumar AM. Music therapy increases serum melatonin levels in patients with alzheimer's disease. Altern Ther Health Med 1999; 5(6): 49-57. (PMID: 10550905).

21. Zhou K, Li X, Li J et al. A clinical randomized controlled trial of music therapy and progressive muscle relaxation training in female breast cancer 
patients after radical mastectomy: Results on depression, anxiety and length of hospital stay. European J Oncol Nursing 2015; 19(1): 54-9. (PMID: 25181938).

22. Palmer JB, Lane D, Mayo D, Schluchter M, Leeming R. Effects of music therapy on anesthesia requirements and anxiety in women undergoing ambulatory breast surgery for cancer diagnosis and treatment: a randomized controlled trial. J ClinOncol 2015; 33(28): 3162-8. (PMID: 26282640).

23. Rossetti $A$, Chadha $M$, Torres $B N$ et al. The impact of music therapy (MT) on anxiety in cancer patients undergoing simulation for radiation therapy (RT). Int J of Radiat Oncol Biol Phys 2017; 99(1): 103-10. (PMID: 28816136).

24. Bilgic S, Acaroglu R. Effects of listening to music on the comfort of chemotherapy patients. West J Nurs Res 2017: 39(6): 745-62. ( PMID: 27515501).

25. Umbrello $M$, Sorrenti $T$, Mistraletti G, Formenti $P$, Chiumello D, Terzoni S. Music therapy reduces stress and anxiety in critically ill patients: a systematic review of randomized clinical trials. Minerva anestesiologica, 2019; 85(8): 886-98. (PMID: 30947484). 